\title{
Development of an Electronic Load Applied to the Characterization of Electric Batteries
}

\author{
Edwin García Quintero ${ }^{1}$, Jose Alfredo Palacio-Fernández*2 \\ TESLA Research Group, Universidad de Antioquia, Medellín, Colombia. \\ ${ }^{1}$ PhD., Professor Universidad de Antioquia Medellín, Colombia. \\ ${ }^{2}$ Phd student, Universidad de Antioquia, Medellín, Colombia. \\ Assistant Professor, Institución Universitaria Pascual Bravo, Medellín, Colombia.
}

\begin{abstract}
People use batteries as sources of power for electrical and electronic devices in their daily life. Nevertheless, these possess temporary supply limitations due to their state of charge (SOC). A technique used to determine the state of charge is counting amperes, identifying the amount of consumed and of missing amperes according to the initial capacity of the battery. An electronic load consisting of an operational amplifier and an IGBT were used in order to maintain a constant current in the battery discharge process, as well as a data acquisition system that specifies the time needed to obtain the variables of current defined by the electronic load, as well as the battery voltage. Without a heatsink, the Ice current of the IGBT does not remain constant, due to temperature increases exceeding $100^{\circ} \mathrm{C}$ in less than a minute. A dissipation system with and without ventilation was needed, and the one that kept the current constant was a heatsink for AMD processor with a thermal solution greater than $90 \mathrm{~W}$ with active ventilation. The discharge curve was managed with it while maintaining the temperature of the IGBT at a maximum value of $46^{\circ} \mathrm{C}$ during the 4.5 hours, with a current of $4.19 \mathrm{~A}$. The initial capacity of the lead acid battery used was close to 19Ah, a little less than that defined by the manufacturer for the new battery $(20 \mathrm{Ah})$. One of the biggest problems in determining the state of charge by means of ampere counting is the accuracy of the sensor. To the current sensor used, you can implement filtering stages that improve the SOC value as future work. It should be used that the Vce is below the battery to be discharged. Therefore, this system could not be implemented in $2 \mathrm{~V}$ batteries, because the Vce voltage in the IGBT exceeds $2 \mathrm{~V}$ and cannot deliver a potential difference in the resistive load.
\end{abstract}

Keywords: IGBT, SOC, heatsink, SOH, discharge, data acquisition

\section{INTRODUCTION}

Electric vehicles and renewable energy systems suitable for industry, businesses and homes are a significant contribution in the face of global warming, affecting the entire planet. All these systems require energetic support from rechargeable batteries to function. In order to deliver energy in optimal conditions that increases their useful life, batteries need to be controlled. Although lead acid batteries that are discarded are an environmental problem, it is also true that, when recovered, they have a recycling percentage of up to $80 \%$ [1], which is much better than lithium batteries [2].

The information provided by the SOC can support the correct decision of starting and stopping the charging and discharging process in order to avoid battery failures, such as overcharge and overdischarge [3]. Several investigations are focused on determining batteries' SOC, as shown in Table 1.

Table 1. Some investigations considering SOC

\begin{tabular}{|c|l|l|}
\hline $\begin{array}{c}\text { Consulted } \\
\text { source }\end{array}$ & \multicolumn{1}{|c|}{$\begin{array}{c}\text { Analyzed } \\
\text { batteries }\end{array}$} & Studied variables \\
\hline$[4]$ & $\begin{array}{l}\text { Lithium ions } \\
\text { (Li-ion) }\end{array}$ & $\begin{array}{l}\text { State of charge } \\
\text { (SOC) and state of } \\
\text { health (SOH) }\end{array}$ \\
\hline$[5]$ & $\begin{array}{l}\text { Lithium ions } \\
\text { (Li-ion) }\end{array}$ & S OC \\
\hline$[6]$ & $\begin{array}{l}\text { Lead acid } \\
\text { (Pb-Acid) } \\
\text { Lithium ions } \\
\text { (Li-ion) }\end{array}$ & $\begin{array}{l}\text { SOC } \\
\text { SOH }\end{array}$ \\
\hline$[7]$ & $\begin{array}{l}\text { Lead acid } \\
\text { (Pb-Acid) }\end{array}$ & $\begin{array}{l}\text { Battery degradation, } \\
\text { i.e. temperature, } \\
\text { charge/discharge } \\
\text { profiles and battery } \\
\text { characteristics, SOC }\end{array}$ \\
\hline
\end{tabular}

The SOC of lead acid battery is the ratio between the current capacity $(\mathrm{CA})$ and the maximum capacity $(\mathrm{CM})$, which varies depending on the state of health ( $\mathrm{SOH})$. The $\mathrm{CM}(\mathrm{Q})$ is the usable capacity at the average discharge rate and current discharge temperature [8]. The relationship between the current 
capacity and the maximum capacity is determined by equation 1.

$$
S o C=\frac{C A}{C M}
$$

The values obtained by integrating current with which CA is obtained are defined in equation 2 [9]

$$
C A=\eta \int_{t_{0}}^{t} I(t)
$$

Where I is the current and $\eta$ is the battery's performance

From the measurement of open circuit and in-line voltage, the SOC can be obtained, taking into account that the battery is 12 volts, the full charge voltage is approximately $12.8 \mathrm{~V}$ (lead acid batteries) and 11.4 when it is discharged [10]. However, it requires having the battery offline, which is suitable for power systems that have long interruptions between working times, and not for interrupted work.

The purpose of this study is to develop an electronic system that extracts the physical variables such as voltage and current to determine the SOC and thus, knowing the initial maximum load capacity, obtain the $\mathrm{SOH}$.

The aging of a battery influences its performance and its output parameters [11], so, as the battery ages, it reduces its initial $\mathrm{SOH}$ by reducing the maximum charge capacity. A battery's $\mathrm{SOH}$ will thus be related to the variation of its current maximum charge with respect to the initial maximum capacity as shown in equation 3 [12].

$$
S O H_{i}(k)=\frac{C_{i, \max }(k)}{C_{i, \text { max } \_n e w}}
$$

Where $\mathrm{k}$ is the value of the $\mathrm{k}$-th cycle of charging and discharging.

The experimental downloading process is carried out by means of an electronic load, which can vary the current ratio required for the battery and discharge it at different speeds [13].

This study analyzes a used battery with a maximum initial capacity of 20Ah (Ampere-hours) when it was new, which has had little use. The data were acquired through an embedded system and an electronic load designed from an IGBT as a power control element, corroborating the values of the manufacturer's data sheet, which calculates the life of the electronic power devices and the conditions under which these fails. Such an estimate of the useful life and reliability tests are generally carried out through the accelerated power cycle. The device is composed of several layers of different materials with different coefficients of thermal expansion. This causes the power modules to experience cutting voltages within their composition, causing deformations and eventually leading to device failure [14]. Tests that allowed defining IGBT behavior before different values of current between collector and emitter, and the stability of the current according to the temperature reached, were carried out.

\section{MATERIALS AND METHODS}

The active and saturation region values for the IGBT GT60M303 for four $\mathrm{V}_{\mathrm{GE}}$, voltage values, according to the device data sheet [15], are shown in Fig. 1.

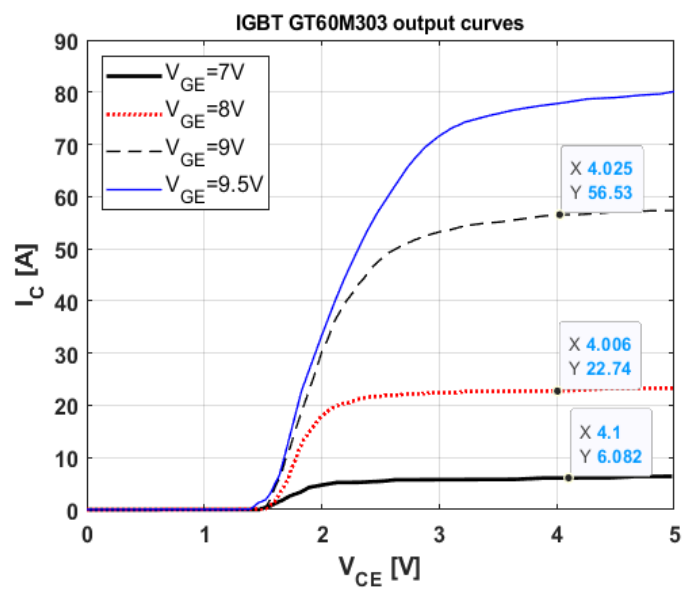

Fig. 1. IGBT output curves

According to the previous curves, electronic charging can be designed to maintain a constant current used in the discharge of a battery for research purposes. Although the maximum current is $60 \mathrm{amps}$ in the IGBT used, the manufacturer's curves project higher levels. Furthermore, as shown in Fig. 2, the maximum current will be limited by the resistor located between F and G, the battery voltage between $\mathrm{A}$ and $\mathrm{B}$ which must be greater than the voltage Vce of approximately $2 \mathrm{~V}$ in which the constant current is less than $22 \mathrm{~A}$ for a determined Vge.

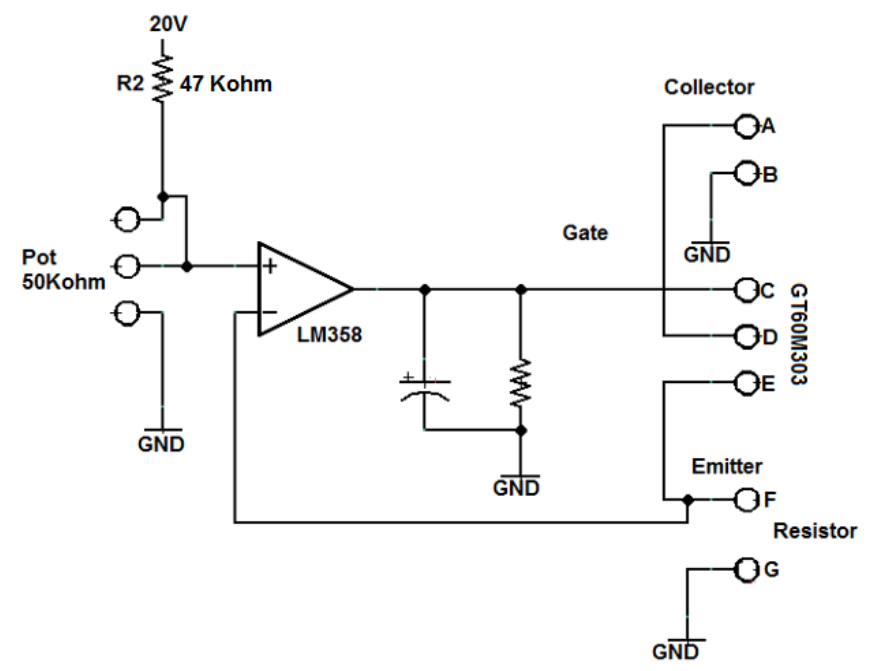

Fig. 2. Basic electronic charging scheme.

The voltage at the load resistance is adjusted to the positive input voltage value of the operational amplifier LM358m, which is adjusted by the voltage divider between $\mathrm{R} 2$ and the Pot potentiometer of Fig. 2. In this case, the maximum value of the voltage divider would be equal to $9.62 \mathrm{~V}$ which would limit the voltage in the load to $9.61 \mathrm{~V}$ and the maximum current to the value of the load resistor itself ( $100 \mathrm{~W} 1 \Omega$ power resistor). 
Fig. 3 shows the electronic load with the heatsink, the IGBT GT60M303 and the resistance that defines the control voltage level (1), the activation system of the IGBT by means of an operational amplifier (2), and the connection for a 12 volts fan (3).

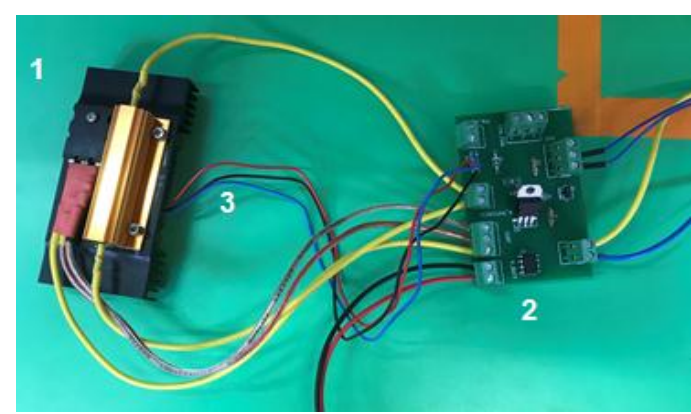

Fig. 3. Electronic load initially designed

In this case, a load resistance of $1 \Omega$ and $100 \mathrm{~W}$ was used, which allows maximum current due to the approximate power of the resistor:

This maximum value must be guaranteed by the voltage divider, and it must not exceed $9.62 \mathrm{~V}$.

An electronic charge was also implemented with a computer heatsink that has a forced ventilation temperature control as shown in Fig. 4.

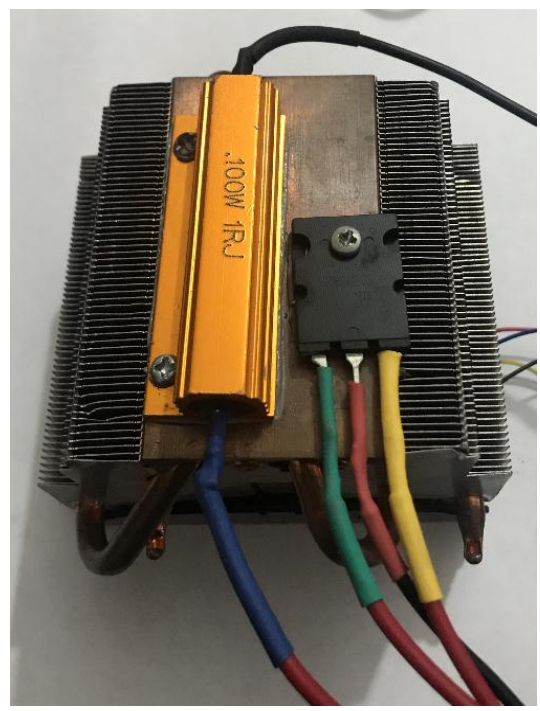

Fig. 4. Heatsink final electronic charge.

To achieve thermal values, a Skeek Thermal camera with a thermal sensor of $206 \times 156$ with a detection range of $-40^{\circ} \mathrm{C}$ to $330^{\circ} \mathrm{C}$ and a field of $36^{\circ}$ was used.

In order to acquire the current and voltage curve to calculate SOC, the current values of electronic loads and the activation control are carried out by means of a data acquisition card built for this. It consists of serial port acquisition, micro SD storage, real-time clock and periodic information capture control every 10 seconds by means of an embedded Arduino Nano system (Fig. 5).

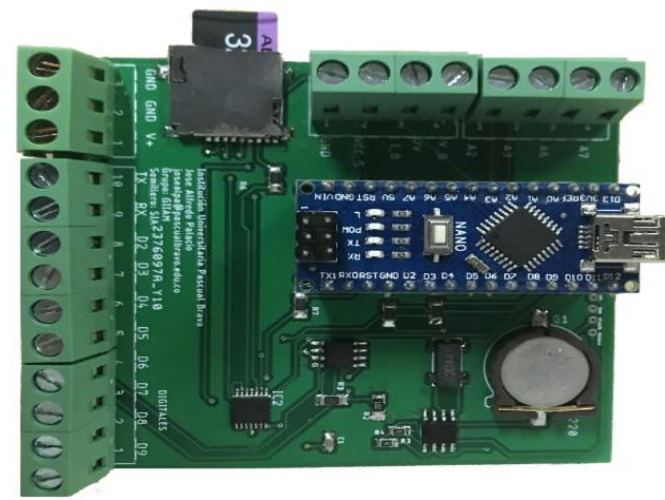

Fig. 5. Implemented data acquisition system

The experiment was carried out using lead acid batteries of 20Ah in initial, healthy conditions. These were subjected to a discharge of 4.19 amps until the voltage dropped semiparabolically, the general scheme for the acquisition of the battery's current discharge and the adaptation for automatic charge (by means of Smart fast charger SON-1210B +).

The embedded system permanently monitors the current to count consumed amps until the voltage drops to a certain value, where the electronic load cannot supply the programmed current and the charging process begins again to complete a full cycle. This project carries out the charging and discharging, yet only the latter is analyzed because the design is focused on electronic charging. The implemented scheme is shown in Fig. 6.

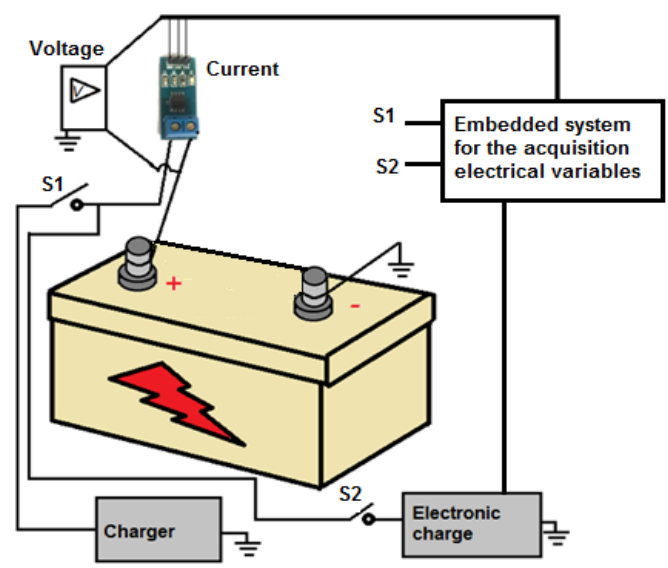

Fig. 6. General scheme of experimental setup

\section{RESULTS}

The current values for the electronic load were projected for a maximum of $10.4 \mathrm{~A}$ (limited by the load resistor). The relationship between the IGBT curve given by the manufacturer was contrasted (approximate value defined in the IGBT data sheet GT60M303) for VGE $=7 \mathrm{~V}$ and the experimental curve, shown in Fig. 7. This figure shows a small variation between these curves, which may be due to differences in environmental conditions between the 
manufacturer's curve and the real one.

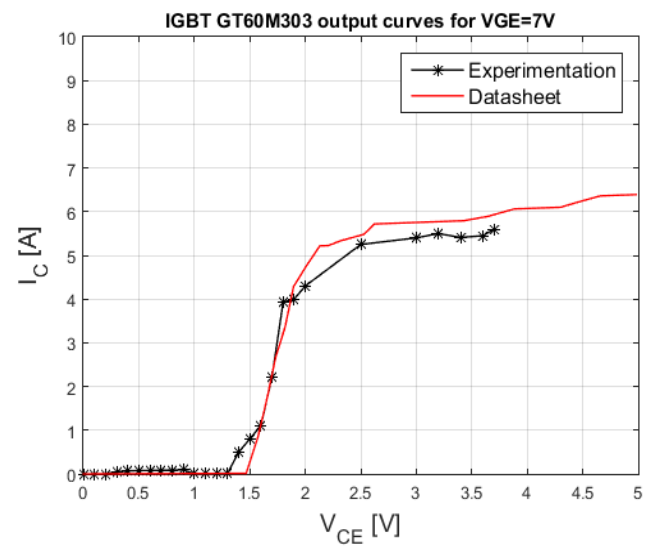

Fig. 7. Experimental check of datasheet for VGE = $7 \mathrm{~V}$

As the objective is to design an electronic load that has constant current, it should be clear that this IGBT is suitable in Vce ranges greater than 2 volts (Fig. 1) for the load with maximum current of $10.4 \mathrm{~A}$ in resistors of $1 \Omega$ or higher amperage for lower value resistors.

The encapsulation temperature increases in the IGBT as the current demanded by the load increases. Thus, for a current of 0.93 amps without a heatsink, the encapsulation temperature goes from $33^{\circ} \mathrm{C}$ to $90^{\circ} \mathrm{C}$ in 2 minutes (Fig. 8), while for a current of 2.11 amps, it goes from $33^{\circ} \mathrm{C}$ to $90^{\circ} \mathrm{C}$ in 30 seconds. A quick disconnection is therefore required since the joint for the IGBT used has a maximum temperature of $150^{\circ} \mathrm{C}$. The maximum temperature value for the IGBT used is $150^{\circ} \mathrm{C}$, which implies that a heatsink must be used to be kept at room temperature so that the Ice current is constant within that limit.

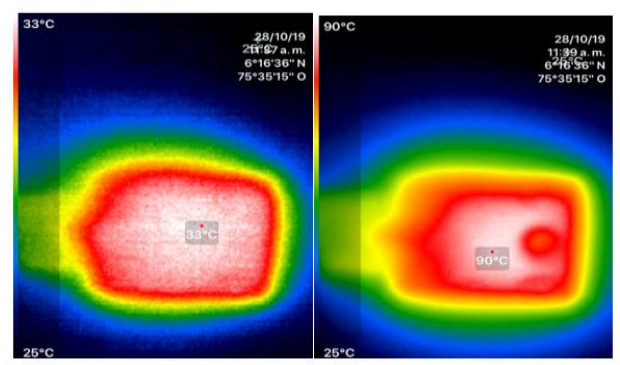

Fig. 8. Minimum and maximum thermal levels experienced in the encapsulation of the GT60M303.

Using an aluminum heatsink increases heating times and reduces the maximum thermal limit reached. Thus, for a $10 \mathrm{~cm}$ $\mathrm{x} 5 \mathrm{~cm}$ heatsink, it is possible to go from $33^{\circ} \mathrm{C}$ to $48^{\circ} \mathrm{C}$ in 2 minutes, subjecting the electronic load to a $974 \mathrm{~mA}$ current; from $33^{\circ} \mathrm{C}$ to $74^{\circ} \mathrm{C}$ in 2 minutes in a current with a $1920 \mathrm{Ma}$ electronic charge; and from $33^{\circ} \mathrm{C}$ to $97^{\circ} \mathrm{C}$ in 2 minutes with a current of $3160 \mathrm{~mA}$.

By adding the forced ventilation system, the temperature of the IGBT in the encapsulation is kept more constant, going from $59^{\circ} \mathrm{C}$ to $61^{\circ} \mathrm{C}$ in 5 minutes, and the Ice current that is recorded remains approximately constant when the load is regulated to 1
Ampere (Fig. 9).

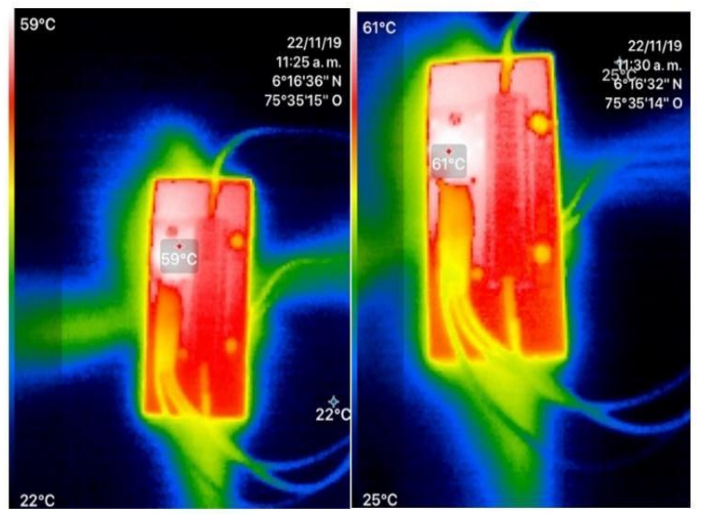

Fig. 9. Minimum and maximum levels achieved with a current of $1 \mathrm{~A}$ and a heatsink with ventilation

For 3 amps, the temperature goes from $39^{\circ} \mathrm{C}$ to $100^{\circ} \mathrm{C}$ in 4 minutes. This indicates that this load with this heatsink fails to evacuate the heat caused by charge movements inside the IGBT, and that, therefore, a heatsink with a greater area of dissipation and air flow in the ventilation is required. To lessen this problem, a heatsink was implemented to maintain a constant temperature, used in the cooling of processors, adapting a temperature and output sensor by PWM. With this type of heatsink, it was possible to keep the temperature almost constant for a fixed current of 4.19 Amps ( Fig. 10), given that in 1 hour and 20 minutes the maximum temperature was $46^{\circ} \mathrm{C}$ and the current, as seen in data acquired by the datalogger, remained almost constant ( Fig. 11). It was also found by means of the ampere count that the battery capacity was $18.85 \mathrm{Ah}$, while the initial maximum capacity battery indicated was 20 Amps, so the battery's current SOH was $94.25 \%$ applying equation 3 .

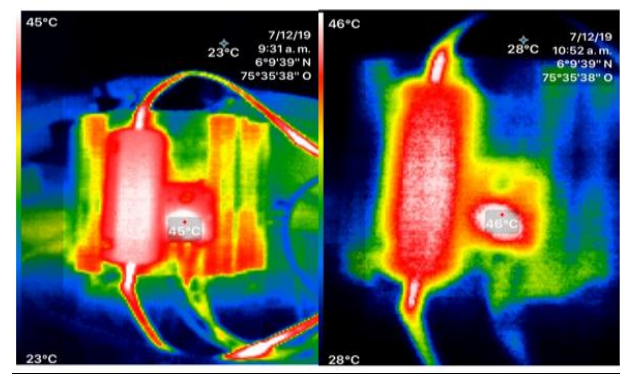

Fig. 10. Thermal levels reached in 1 hour 30 minutes

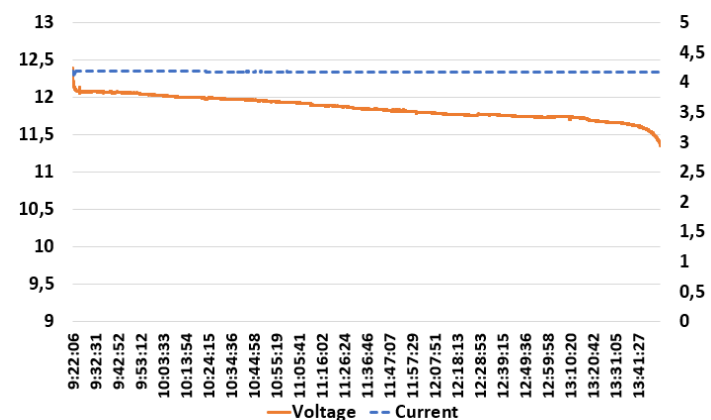

Fig. 11. Current (right axis) and voltage (left axis) values obtained in a discharge cycle 


\section{CONCLUSIONS}

Electronic loads must have a proper cooling system that maintains a constant discharge current in order to deliver an accurate SOC value.

The design of the IGBT charges must ensure that the Vce is well below the battery to be discharged. Thus, this system could not have been implemented in $2 \mathrm{~V}$ batteries, because the Vce voltage in the IGBT exceeds $2 \mathrm{~V}$ and could not deliver a potential difference in the resistive load. Moreover, the system would be in the saturation zone and not in the linear region where the current remains constant.

Experimentation was based on an already established IGBT model for which it was possible to approximate the curve under controlled conditions.

The electronic load manages to maintain the current at $4.19 \mathrm{~A}$ for an approximate temperature of $46^{\circ} \mathrm{C}$, as indicated in Fig. 11. There are small fluctuations at the beginning, while a constant thermal level is reached.

\section{RFERENCES}

[1] A y G Ingenieria SAS, «A y G Ingenieria SAS » Historia,» 2015. [En línea]. Available: https://fundimetal.com/company/historia/.

[2] S. M. A. S. Bukhari, J. Maqsood, Q. M. Baig, S. Ashraf y T. A. Khan, «Comparison of Characteristics--Lead Acid, Nickel Based, Lead Crystal and Lithium Based Batteries,» de 17th UKSim-AMSS International Conference on Modelling and Simulation, Washington, 2015.

[3] S. Yuan, H. Wu y C. Yin, «State of Charge Estimation Using the Extended Kalman Filter for Battery Management Systems Based on the ARX Battery Model,» energies, pp. 444-470, 2013.

[4] S. A. B. \&. P. P. Dey, «Combined estimation of Stateof-Charge and State-of-Health of Li-ion battery cells using SMO on electrochemical model,» Proceedings of IEEE Workshop on Applications of Computer Vision, pp. 1-6, 2014.

[5] E. T. Q. T. \&. M. K. Kruger, «Normalized least mean squares observer for battery parameter estimation,» de IEEE Eindhoven PowerTech, Eindhoven, 2015.

[6] C. \&. M. O. Lashway, «Adaptive Battery Management and Parameter Estimation through Physics Based Modeling and Experimental Verification,» IEEE Transactions on Transportation Electrification, vol. 2, $\mathrm{n}^{\mathrm{o}}$ 4, pp. 454-464, 2016.

[7] A. \&. H. A. Rajabi-Ghahnavieh, «Explicit degradation modelling in optimal lead-acid battery use for photovoltaic systems,» IET Generation, Transmission \& Distribution, vol. 10, no 4, p. 1098-1106, 2016.

[8] P. Krivík, «Methods of SoC determination of lead acid battery,» Journal of Energy Storage, pp. 191-195, 2018.

[9] D. Huang, Z. Chen, C. Zheng y H. Li, «A model-based state-of-charge estimation method for series-connected lithium-ion battery pack considering fast-varying cell temperature,» Energy, p. 847e861, 2019.

[10] V. K. Prasad y B. P. Divakar, «International Journal of Renewable Energy Research,» Real time estimation of SoC and SoH of batteries., vol. 8, nº 1, pp. 44-55, 2018.

[11] N. Kularatna, «Dynamics and modeling of rechargeable batteries: what electrochemists? work tells the electronic engineers,» IEEE Power Electronics Magazine, vol. 1, n 4, pp. 23-33, 2014.

[12] T. Kim, W. Qiao y L. Qu, «Online SOC and SOH Estimation for Multicell Lithium-ion Batteries Based on an Adaptive Hybrid Battery Model and Sliding-Mode Observer,» de IEEE Energy Conversion Congress and Exposition, Raleigh, 2013.

[13] Y. W. Wong, L. W. Chong, R. K. Rajkumar, W. Y. Leng y R. K. Rajkumar, «A new state-of-charge estimation method for valve regulated lead acid batteries,» Journal of Engineering Science and Technology, pp. 584 - 595, 2017.

[14] A. Stupar, D. Bortis, U. Drofenik y J. W. Kolar, «Advanced Setup for Thermal Cycling of Power Modules following Definable Junction Temperature Profiles,» de International Power Electronics Conference, Sapporo, 2010.

[15] Toshiba, «GT60M303,» 67 2004. [En línea]. Available: https://www.es.co.th/Schemetic/PDF/GT60M303.PDF. [Último acceso: 10 2019]. 